\title{
An EXAFS Study on Sr and Cs Speciation in Clayey Soils at Nuclear Legacy Sites
}

\author{
P. BOTS ${ }^{1}$, R. LUNN ${ }^{1}$, M.J. COMARMOND ${ }^{2}$, T.E. PAYNE ${ }^{2}$, \\ J.C. RENSHAW ${ }^{1}$ \\ ${ }^{1}$ Department of Civil and Environmental Engineering, \\ University of Strathlcyde, Glasgow, G1 1XJ, UK \\ ${ }^{2}$ Australian Nuclear Science and Technology Organisation, \\ Lucas Heights, NSW 2234, Australia
}

Through more than 60 years of nuclear power generation, and a longer history of nuclear research, many legacy waste sites with stored radioactive wastes exist throughout the world. Such legacy sites include Savannah River (NC, USA), ${ }^{1}$ Sellafield (Cumbria, UK) ${ }^{2}$ and the Little Forest Legacy Site (NSW, Australia). ${ }^{3}$ The location of such sites was often chosen based on the local geology and soil composition. For example, the Little Forest Legacy Site was chosen based on the clayey nature of the soils and rocks present $(\sim 50 \%$ kaolinite and illite-smectite), limiting water movement and migration of radioactive contaminants. ${ }^{3,4}$ However, despite the clay-rich environment, radioactive contaminants (including fission products and actinides) have been detected in sediments, groundwater, surface runoff and vegetation at the Little Forest Legacy Site. ${ }^{4,5}$ In order to ensure continued safe management of the site, as well as to develop new engineering stategies for radwaste containment and / or cleanup, an improved understanding of the geochemistry of radioactive contaminants is required. ${ }^{6}$

For this presentation we focused on the geochemical speciation of $\mathrm{Sr}$ and $\mathrm{Cs}$ in contact with clay minerals and a composite clayey soil. ${ }^{7}$ We performed a comprehensive set of adsorption experiments and XAS analyses. Subsequently, in order to obtain detailed information we utilized two EXAFS fitting strategies. The first, a semi-shell-by-shell strategy of the EXAFS, was used to determine the $\mathrm{Sr}$ and $\mathrm{Cs}$ surface complexes on the clay minerals. The second (based on the identified surface complexes) provided details on the complexation / distribution of $\mathrm{Sr}$ and Cs within a clayey soil.

References

[1] Hakem et al. Radiochim Acta 92, 419-432, (2004).

[2] Wallace et al. Appl Geochem 27, 1482-1491, (2012).

[3] Payne. Background Report on the Little Forest Burial Ground Legacy Waste Site. (ANSTO, 2012). [4] Cendón et al. Aust J Earth Sci 62, 123-141, (2015). [5] Payne et al. Environ Sci Technol 47, 13284-13293, (2013). [6] Upgrading of near surface repositories for radioactive waste, (IAEA, Vienna, 2005). [7] Yamaguchi et al. J Radioanal Nucl Ch 317, 545-551, (2018). 